\title{
Análise das características termo higrométricas de transectos móveis noturnos em episódios de inverno em Maringá-PR
}

\author{
C. Minaki ${ }^{(a)}$ \\ (a) Professora do Departamento de Geografia da Universidade Estadual de Maringá, cminaki@uem.br
}

Eixo: 3 - Climatologia em diferentes níveis escalares: mudanças e variabilidades

\section{Resumo}

As ilhas de calor consistem em áreas que se distinguem pelo contraste de temperatura e umidade relativa do ar do seu entorno. Tendo em vista o sistema urbano de Maringá, buscou-se analisar se as modificações ocorridas neste município paranaense de porte populacional médio, propiciam a formação da ilha de calor noturna. Utilizou-se a metodologia do transecto móvel para o registro térmico e higrométrico, em dez episódios representativos do inverno de 2016. A extensão do transecto caracterizou-se pelo uso da terra diferenciado, e aspectos de superfície e densidade de edificações e de vegetação variadas. Obteve-se diferença térmica de até $6,4^{\circ} \mathrm{C}$ e higrométrica máxima de $27 \%$, sob condições sinóticas estáveis. Sob influência de sistemas polares, parte do percurso localizada na zona 28, com altitude menor que a das outras áreas, variando entre 473 a $488 \mathrm{~m}$, registrou valores extremos menores para a temperatura e maiores para a umidade relativa do ar.

Palavras chave: Ilha de calor noturna. Temperatura do ar. Umidade relativa do ar. Transecto móvel. MaringáPR.

\section{Introdução}

As ilhas de calor consistem em áreas que se distinguem daquelas do seu entorno, pelo maior aquecimento gerado pelo acúmulo de calor, principalmente nas áreas mais adensadas dos espaços urbanos. Gordon Manley, em 1958, denominou isla de calor urbana a diferença de temperatura entre o centro e as áreas periféricas da cidade, observando também que nesta circunstância, há uma diferença de umidade, inversamente proporcional à temperatura, a qual denominou isla de sequedad (CARRERAS et al., 1990, p. 54).

Sabe-se que a ocorrência espacial e temporal da ilha de calor urbana pode ser variada, manifestandose, inclusive, em mais de uma área ao mesmo tempo ou conforme a época do ano. Oke (1973) antecipou a conclusão de muitos estudos contemporâneos, cujo enfoque não correspondeu a espaços metropolitanos, reconhecendo a possibilidade das cidades de porte populacional pequeno desenvolverem seu clima urbano e a ilha de calor, como constatado por exemplos brasileiros, tais como os de Zamparoni (1995), Minaki e Amorim (2008), Fialho (2009), Frasca Teixeira e Amorim (2016). 
Comumente, a formação da área mais aquecida segue a lógica da ocupação urbana e do desenvolvimento local, na constituição de espaços favoráveis à concentração de pessoas, edificações, serviços e atividades poluentes, em detrimento da vegetação urbana. Particularidades como a dinâmica dos ventos e as feições do relevo, são aspectos que devem ser evidenciados na busca pela compreensão do fenômeno. Prats et al. (2005) destacaram a influência dos ventos no deslocamento da ilha de calor urbana em Zaragoza (Espanha), responsáveis pela configuração de três modelos espaciais. Alcoforado e Andrade (2006), por sua vez, interpretaram as diferenças térmicas obtidas nas áreas de morro (baixada e topo), com vento e sob condição de calmaria, em estações distintas em Lisboa.

Monteiro (1976) ao propor o Sistema Clima Urbano (S.C.U.) previu para cada subsistema um mecanismo de ação de seus produtos. Para o subsistema termodinâmico, no qual um dos produtos é a ilha de calor, o mecanismo é a transformação do espaço, cuja responsabilidade é compartilhada entre o homem e a natureza. No entanto, esse intercâmbio não supera os riscos submetidos pelo estado de equilíbrio dinâmico vislumbrado pelo homem em seu habitat.

Tal como Sousa (1993, p. 143) alertou, o sistema climático não reage imediatamente com o desacelerar dos processos de entropia, desfavorecendo a identificação da representatividade de cada ação dentro do mesmo. Logo, tão complexo quanto compreender o funcionamento das cidades é delimitar o momento em que este equilíbrio dinâmico se rompe.

Sendo assim, buscou-se analisar se as modificações intraurbanas ocorridas neste município paranaense de porte populacional médio, propiciam a formação da ilha de calor noturna. Maringá teve o incremento de mais de 100000 habitantes entre os censos demográficos de 1991 e 2010 do Instituto Brasileiro de Geografia e Estatística (IBGE). Paralelamente ao ritmo do crescimento, houve a prática de políticas de desenvolvimento para tornar o local, polo econômico da região.

Quanto ao período de maior intensidade, muitos estudos reforçaram a ilha de calor noturna (SEZERINO; MONTEIRO, 1990; MENDONÇA, 1994; ALCOFORADO; ANDRADE, 2006; FIALHO, 2009), considerando que a área urbana demora mais tempo que a rural, para dissipar na atmosfera todo o calor estocado por suas edificações e geometria ao longo do dia.

A estação de inverno, período em que grande parte das cidades brasileiras passa por uma redução na quantidade de precipitação, e registra condições de tempo anticiclônico, destaca-se como época propícia para a verificação da ilha de calor em comparação com a sua estação oposta (verão). No entanto, outono também se sobressai por ser uma estação de transição que antecipa algumas características do inverno, como verificado nos resultados de Brandão (1996) para a cidade do Rio de Janeiro. 
Baseou-se, portanto, nos levantamentos noturnos de temperatura e umidade relativa do ar, realizados na época mais fria e seca da cidade, mas não se descartando a possibilidade de que medições nas estações de transição e na estação oposta apresentem resultados significativos.

\section{Materiais e procedimentos metodológicos}

Utilizou-se a metodologia do transecto móvel, adaptada de Oke e Maxwell (1975), aplicada por autores como Gomez e García (1984), Pitton (1997) e Amorim, Sant'Anna Neto e Dubreuil (2009). Carreras et al. (1990, p. 57) baseados em Javier Martín-Vide (1987), mencionaram que Schimidt foi o primeiro a usar este procedimento em Viena no ano de 1930, momento em que foi considerado instrumento útil para observar as diferenças térmicas entre a cidade e os seus arredores.

A delimitação do transecto consistiu na escolha de um percurso para a realização de medidas móveis de dois elementos climáticos, a temperatura e a umidade relativa do ar. O percurso feito de automóvel com velocidade de até $30 \mathrm{~km} / \mathrm{h}$, teve duração aproximada de 50 minutos, no sentido norte-sul da malha urbana de Maringá. Buscou-se condições atmosféricas reconhecidas como ideais para a verificação dos efeitos mais intensos da ilha de calor atmosférica, como dias claros, calmos ou com ventos fracos, "uma vez que mais energia solar é capturada em dias claros, e ventos mais brandos removem o calor de maneira mais vagarosa, fazendo com que a ilha de calor se torne mais intensa" (GARTLAND, 2010, p. 18). Em condições anticiclônicas, a existência de um campo de baixa pressão na cidade, receptor de ar mais frio advindo da "periferia", em noites sem circulação regional, proporciona perdas de ar mais quente em altitude (SOUSA, 1993, p. 196). Em razão disso, as medições ocorreram sempre às $21 \mathrm{~h}$, cerca de três horas após o pôr do sol, quando as temperaturas ainda não registraram mudanças tão significativas.

Realizou-se os transectos móveis noturnos em dezoito dias no período de junho a agosto de 2016, no entanto, dez episódios foram selecionados como os mais representativos, posterior a análise das condições sinóticas que anteciparam as medições.

Utilizou-se para a obtenção das temperaturas, um termo higrômetro digital com sensor externo, modelo TH-03B, da marca Impac. A escolha do instrumento ocorreu após calibração realizada tendo como parâmetro os termômetros de bulbo seco e de bulbo úmido utilizados na Estação Climatológica Principal de Maringá (ECPM), que fornecem os dados da temperatura do ar seco e do ar úmido, respectivamente. A temperatura do ar úmido é fundamental para o cálculo da umidade relativa do ar.

Durante os transectos, os elementos climáticos foram registrados a cada 30 segundos, sendo que também se utilizou um aparelho móvel receptor de GPS, modelo Etrex Venture HC, da marca Garmin, programado no mesmo intervalo de tempo que o sensor, para obter as coordenadas de cada ponto no 
sistema Universal Transversa de Mercator (UTM). Ambos os instrumentos funcionaram com o horário padronizado, segundo o fuso oficial de Brasília.

$\mathrm{O}$ trajeto de aproximadamente $16 \mathrm{~km}$ (Figura 1) caracterizou-se pelo uso misto e diversidade de densidade de vegetação, de população e de edificações. Os pontos de início e fim do percurso caracterizaram-se pela maior distância do centro da cidade, sendo o primeiro mais vegetado e de superfícies permeáveis, com uso agrícola, tendo proximidade com o final da Avenida Kakogawa e o início da Estrada do Guerra, fora do perímetro urbano. Por sua vez, o ponto final do transecto ocorreu na Avenida Carmem Miranda, próximo às Chácaras Aeroporto e à Estrada Octávio Colii, que dá acesso ao município de Sarandi, com o qual Maringá se conurba. Foram ainda abrangidas pelos percursos, as avenidas Morangueira (trecho da rodovia PR-317), Colombo (trecho da rodovia BR376), Herval, Cerro Azul, Arquiteto Nildo Ribeiro da Rocha, dentre outras ruas menores.

Visando o acompanhamento da variação dos elementos térmico e higrométrico no intervalo das $21 \mathrm{~h}$ às 22h, verificou-se o banco de dados da estação de superfície denominada Estação Climatológica Principal de Maringá (ECPM), localizada no campus principal da Universidade Estadual de Maringá, a $23^{\circ} 25^{\prime}$ de latitude sul e $51^{\circ} 57^{\prime}$ de longitude oeste, com altitude relativa de $542 \mathrm{~m}$. A ECPM desde 1979 pertence à rede de estações do Instituto Nacional de Meteorologia (INMET). O INMET, por sua vez, representa o Brasil perante a Organização Meteorológica Mundial (OMM), portanto, todas as mais de 400 estações de sua rede compõem o sistema mundial de coleta de dados meteorológicos, utilizando procedimentos padronizados e internacionalmente reconhecidos. Além da elaboração dos boletins meteorológicos nos horários-padrão, às $9 \mathrm{~h}, 15 \mathrm{~h}$ e $21 \mathrm{~h}$, segundo o fuso oficial do Brasil, a ECPM mantém o banco de dados meteorológicos durante o expediente dos observadores, atividade denominada "Marcha horária". A cada hora ocorre a mensuração e registro da temperatura do ar seco, umidade relativa do ar, velocidade e direção do vento e pressão atmosférica.

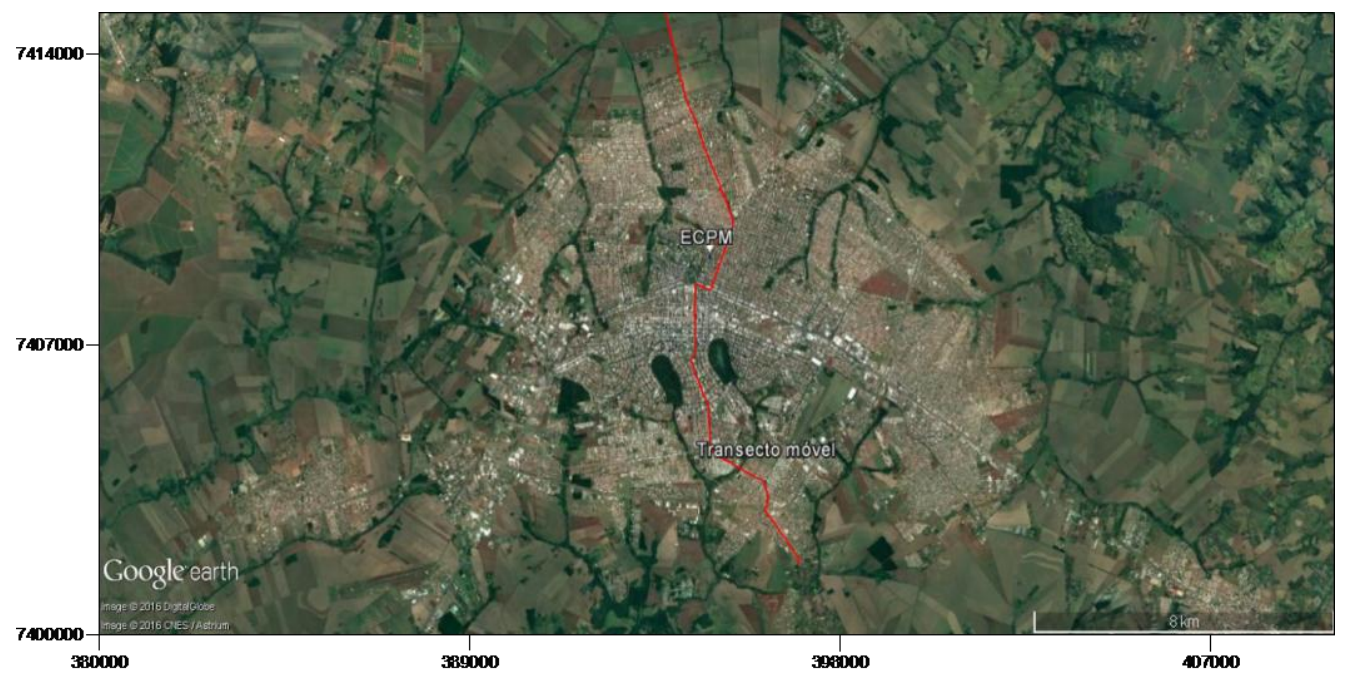

Figura 1 - Transecto móvel norte-sul e localização da Estação Climatológica Principal de Maringá (ECPM) 
Fonte da imagem: Google Earth (2016).

Com os dados da "Marcha horária", considerou-se que se houvesse uma variação de temperatura na ECPM maior que $1{ }^{\circ} \mathrm{C}$ no intervalo das $21 \mathrm{~h}$ às $22 \mathrm{~h}$, a diferença térmica obtida no transecto não poderia ser considerada resultante da ilha de calor. Esse limiar foi definido, pois abrange situações em que a modificação das condições atmosféricas durante o transecto, podem ser atribuídas à atuação dos diferentes tipos de tempo nos locais de coleta dos dados. Por outro lado, o registro de ventos superiores a $2,0 \mathrm{~m} / \mathrm{s}$ indicaria situação de instabilidade provocada pela circulação regional, configurando o desfazimento da ilha de calor, tendo em vista que, Gartland (2010) ressaltou a possibilidade de ocorrência de ilha de calor sob ventos de intensidade fraca.

Concomitante à análise dos dados da ECPM, fez-se a identificação dos sistemas atmosféricos atuantes em cada episódio, medida finalizada pela observação das imagens do satélite meteorológico GOES-13 e da análise sinótica, ambos os produtos disponibilizados no endereço eletrônico do Centro de Previsão de Tempo e Estudos Climáticos/ Instituto Nacional de Pesquisas Espaciais (CPTEC/INPE).

\section{Caracterização da área de estudo}

Maringá localiza-se entre os paralelos $23^{\circ} 15^{\prime}$ e $23^{\circ} 34^{\prime}$ de latitude sul e as longitudes a oeste de Greenwich de $51^{\circ} 50^{\prime}$ a 52 $06^{\prime}$ (Figura 2), com altitudes que variam de 360 a $599 \mathrm{~m}$, na Mesorregião do Norte Central Paranaense. A população estimada é de 403063 habitantes (IBGE, 2016), com área total de $487 \mathrm{~km}^{2}$ (IBGE, 2015), e densidade demográfica de 733 hab $/ \mathrm{km}^{2}$ (IBGE, 2010).

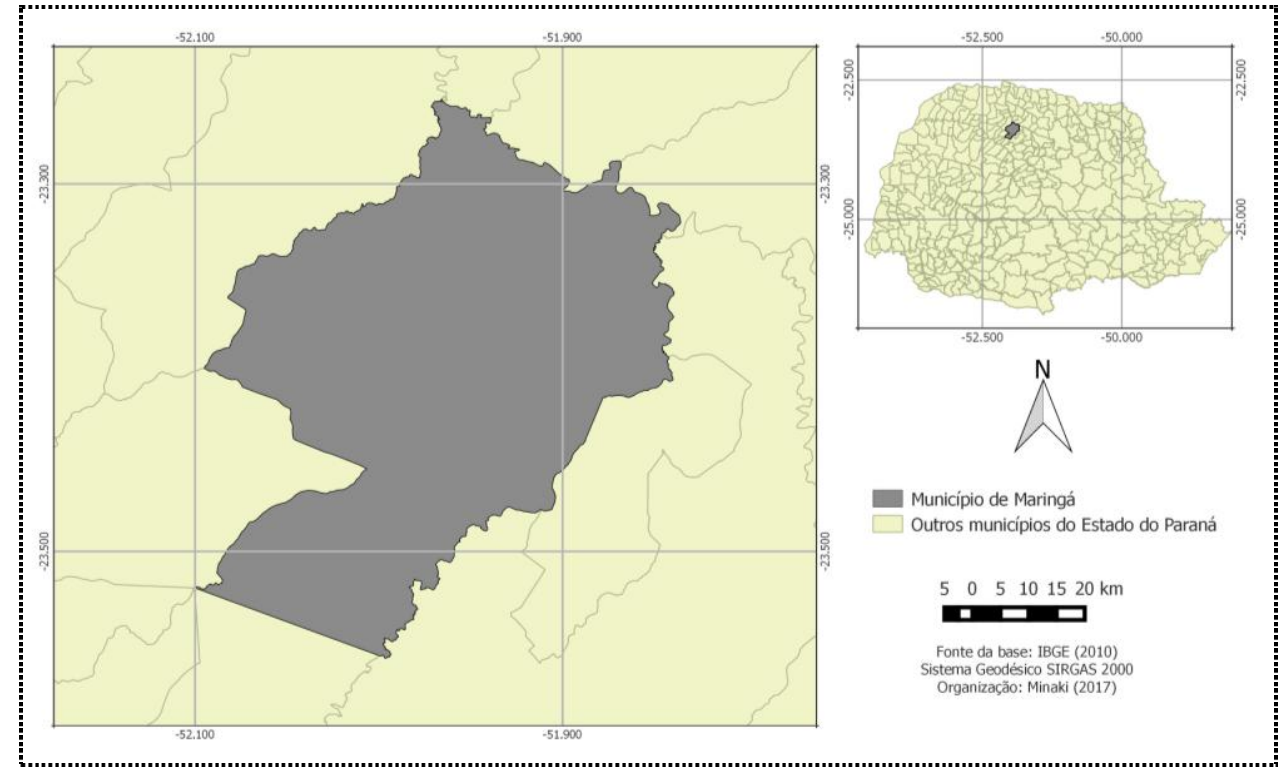

Figura 2 - Localização de Maringá-PR 
XVII Simpósio Brasileiro

de Geografia Fisica Aplicada

I Congresso Nacional

de Geografia Física
OS DESAFIOS DA GEOGRAFIA FÍSICA NA FRONTEIRA DO CONHECIMENTO

Instituto de Geociências - Unicamp

Campinas - SP

28 de Junho à 02 de Julho de 2017

O município está incluído na área da Formação Santo Anastácio do Grupo Bauru. Estende-se por espigões longos, que são aplainados e possuem leve ondulação nos topos dos divisores de água, entre as bacias hidrográficas do rio Pirapó e do rio Ivaí (SILVEIRA, 2003, p. 65). Na área do Terceiro Planalto ou Planalto de Guarapuava, na qual Maringá se inclui, predominam os Latossolos e os Nitossolos (BHERING; SANTOS, 2008, p. 54-55).

Economicamente, a área se destaca no setor agrícola, favorecido pela presença de solos férteis e pelo comércio. Desde a sua elevação à categoria de município pela Lei Estadual nº 790, de 14 de novembro de 1951, ocorre um aumento populacional que requer cuidados para a manutenção da qualidade ambiental local.

O clima caracteriza-se por duas estações do ano bem definidas, sendo o verão chuvoso e o inverno seco. Devido a sua localização nas menores latitudes da região Sul do Brasil, predomina um clima de transição entre o tropical e o subtropical, o que lhe confere características de ambos os regimes climatológicos. Há uma "acentuada variação do tempo atmosférico tanto anual, sazonal, como mensal e diária, especialmente dos pontos de vista térmico e pluviométrico" (SILVEIRA, 2003, p. 33). Durante o ano recebe atuações dos sistemas atmosféricos tropicais, extratropicais e individualizados.

A Figura 3 apresenta o climograma da área. Pela série histórica dos elementos climáticos, de 1979 a 2015, registrada pela ECPM tem-se os seguintes valores médios anuais: 1681,1 mm de precipitação, $23,3^{\circ} \mathrm{C}$ de temperatura média do ar, $27,8^{\circ} \mathrm{C}$ de temperatura média máxima e $17,9^{\circ} \mathrm{C}$ de temperatura média mínima.

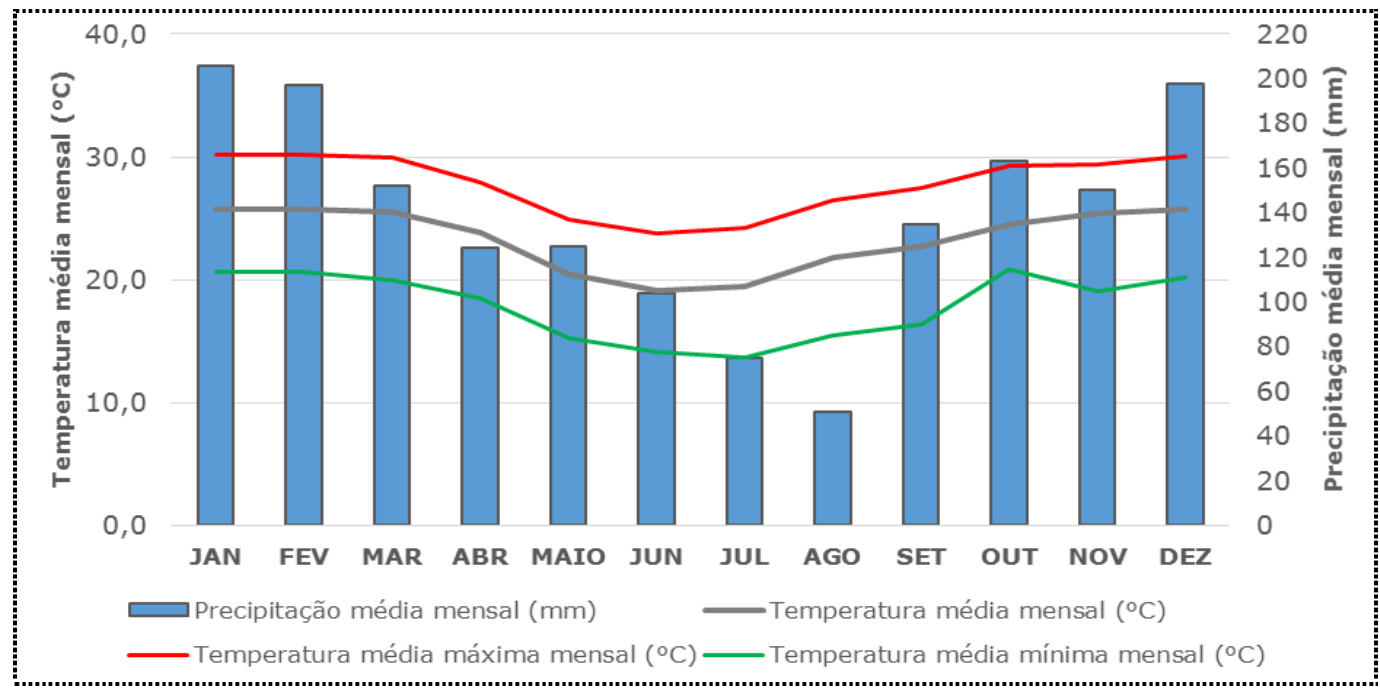

Figura 3 - Climograma de Maringá-PR (1979 a 2015)

Fonte dos dados: ECPM (2016) 


$\begin{aligned} & \text { XVII Simpósio Brasileiro } \\ & \text { de Geografia Fisica Aplicada }\end{aligned}$
$\begin{aligned} & \text { I Congresso Nacional } \\ & \text { de Geografia Física }\end{aligned}$

Pela Figura 3 observa-se que os meses mais chuvosos, em média, foram dezembro, janeiro e fevereiro, com $198 \mathrm{~mm}, 206 \mathrm{~mm}$ e $197 \mathrm{~mm}$, respectivamente, que também registraram as maiores médias térmicas, com $25,8^{\circ} \mathrm{C}$ para o último e para o primeiro mês do ano, e $25,7^{\circ} \mathrm{C}$ para o segundo mês do ano. Os meses mais secos foram junho, julho e agosto, com $104 \mathrm{~mm}, 75 \mathrm{~mm}$ e $51 \mathrm{~mm}$, respectivamente, que também registraram as menores médias térmicas, nos valores de $19,1^{\circ} \mathrm{C}, 19,4^{\circ} \mathrm{C}$ e $21,9^{\circ} \mathrm{C}$, respectivamente. As maiores temperaturas médias máximas alcançaram $30,2^{\circ} \mathrm{C}$ e $30,1^{\circ} \mathrm{C}$, sendo a primeira verificada em janeiro e fevereiro, e a segunda em dezembro. As menores temperaturas médias mínimas foram registradas em maio, junho e julho, alcançando $15,3^{\circ} \mathrm{C}, 14,1^{\circ} \mathrm{C}$ e $13,7^{\circ} \mathrm{C}$, respectivamente.

\section{Análise dos resultados}

Nos dez episódios selecionados a maior diferença térmica obtida nos transectos noturnos foi nos dias 27/07/2016 e 28/08/2016, no valor de $6,4^{\circ} \mathrm{C}$, sendo que no mesmo episódio do dia 27/07/2016, registrou-se a maior diferença higrométrica, no valor de $27 \%$. A menor diferença térmica ocorreu no dia $14 / 06 / 2016$, e foi $4,2^{\circ} \mathrm{C}$. Por sua vez, a menor diferença de umidade relativa do ar foi de $15 \%$, verificada nos dias 28 e 30/06/2016.

A Tabela I resume as principais informações quantitativas obtidas nos transectos, sendo também subsídio para a discussão das condições atmosféricas de cada episódio.

Tabela I - Informações dos transectos por episódio

\begin{tabular}{|c|c|c|c|c|c|c|}
\hline Episódio & $\begin{array}{c}\text { Menor } \\
\text { temperatura } \\
\text { registrada no } \\
\text { transecto }\left({ }^{\circ} \mathbf{C}\right)\end{array}$ & $\begin{array}{c}\text { Maior } \\
\text { temperatura } \\
\text { registrada no } \\
\text { transecto }\left({ }^{\circ} \mathbf{C}\right)\end{array}$ & $\begin{array}{c}\text { Menor } \\
\text { umidade } \\
\text { relativa do ar } \\
\text { registrada no } \\
\text { transecto }(\%)\end{array}$ & $\begin{array}{c}\text { Maior } \\
\text { umidade } \\
\text { relativa do ar } \\
\text { registrada no } \\
\text { transecto }(\%)\end{array}$ & $\begin{array}{l}\text { Diferença das } \\
\text { temperaturas } \\
\text { extremas do } \\
\text { transecto }\left({ }^{\circ} \mathbf{C}\right)\end{array}$ & $\begin{array}{c}\text { Diferença } \\
\text { higrométrica } \\
\text { do transecto } \\
(\%)\end{array}$ \\
\hline $\begin{array}{l}\text { 1: } 14 / 06 / 2016 \\
\text { (Terça-feira) }\end{array}$ & "11,8 & 16 & 67 & 84 & 4,2 & 17 \\
\hline $\begin{array}{l}\text { 2: 28/06/2016 } \\
\text { (Terça-feira) }\end{array}$ & 14,7 & 19,1 & 57 & 72 & 4,4 & 15 \\
\hline $\begin{array}{l}\text { 3: 30/06/2016 } \\
\text { (Quinta-feira) }\end{array}$ & 15,9 & 20,4 & 60 & '75' & 4,5 & "15' \\
\hline $\begin{array}{l}\text { 4: 04/07/2016 } \\
\text { (Segunda- } \\
\text { feira) }\end{array}$ & 16,8 & 21,8 & 50 & 66 & 5,0 & 16 \\
\hline $\begin{array}{l}\text { 5: } 11 / 07 / 2016 \\
\text { (Segunda- } \\
\text { feira) }\end{array}$ & 17,6 & 23,8 & 48 & 67 & 6,2 & 19 \\
\hline $\begin{array}{l}\text { 6: 20/07/2016 } \\
\text { (Quarta-feira) }\end{array}$ & 12,4 & 16,9 & 58 & 76 & 4,5 & 18 \\
\hline $\begin{array}{l}\text { 7: 27/07/2016 } \\
\text { (Quarta-feira) }\end{array}$ & 12 & 18,4 & 45 & 72 & 6,4 & 27 \\
\hline $\begin{array}{l}\text { 8: 01/08/2016 } \\
\text { (Segunda- } \\
\text { feira) }\end{array}$ & 17,5 & 23 & 47 & 72 & 5,5 & 25 \\
\hline
\end{tabular}




\begin{tabular}{|c|c|c|c|c|c|c|}
\hline $\begin{array}{c}\text { 9: } 22 / 08 / 2016 \\
\text { (Segunda- } \\
\text { feira) }\end{array}$ & 9,1 & 14,1 & 58 & 81 & 5,0 & 23 \\
\hline $\begin{array}{c}\text { 10: } \\
\text { 28/08/2016 } \\
\text { (Domingo) }\end{array}$ & 19,5 & 25,9 & 38 & 58 & 6,4 & 20 \\
\hline
\end{tabular}

Fonte dos dados: Trabalho de campo (2016).

Notou-se pela observação das cartas sinóticas que, na metade do período analisado houve a influência da Alta Subtropical do Atlântico Sul (ASAS) nos três episódios de junho e no episódio de 04/07/2016. As condições meteorológicas registradas pela ECPM relacionaram-se às da Massa Tropical Atlântica (MTA), com ventos diurnos vindos do quadrante leste, temperaturas amenas variando aproximadamente de $18^{\circ} \mathrm{C}$ a $26^{\circ} \mathrm{C}$, e umidade relativa do ar de moderada a alta, com registros entre $40 \%$ a quase $70 \%$.

No dia 14/06/2016 verificou-se temperaturas menores, no entanto, as condições sinóticas que antecederam esta data (08 a 13/06/2016), incluindo as temperaturas mínimas e máximas, variaram de $3,4^{\circ} \mathrm{C}$ a $20,1^{\circ} \mathrm{C}$, ventos dos quadrante Sul e pressão acima de $960 \mathrm{hPa}$ indicaram a presença da Massa Polar Atlântica (MPA) e de sua derivada, a Massa Polar Velha (MPV). Grande parte das condições sinóticas ocorridas em 14/06/2016 demonstrou a mudança do sistema atmosférico atuante, no entanto, as temperaturas do ar mantiveram-se baixas ao longo do dia.

Por sua vez, no dia 11/07/2016 além da influência da Massa Tropical Atlântica (MTA) também observou-se queda da pressão atmosférica, elevação das temperaturas no período de maior aquecimento diurno e aumento da nebulosidade, contrastando com temperaturas baixas durante a noite provocadas pela presença de uma frente fria estacionária na região Sul do Brasil.

No episódio do dia 20/07/2016, observou-se pelo conjunto de dados analisados, a influência da Massa Polar Atlântica (MPA) com ventos do quadrante sul de velocidade baixa. Nos dias 27/07/2016 e 01/08/2016 houve o predomínio de um sistema frontal, havendo principalmente no dia 27/07/2016, a diminuição das temperaturas, com aspectos sinóticos de transição entre a Frente Polar Atlântica (FPA) e a Massa Polar Atlântica (MPA). No dia 22/08/2016 houve novamente a atuação da Massa Polar Atlântica (MPA) sobre a área e no dia 28/08/2016 observou-se a presença da frente fria estacionária associada ao ar polar em toda a região Sul do país, aumentando a nebulosidade.

Considerando que em nenhum dos episódios selecionados, a variação dos elementos temperatura e ventos entre às $21 \mathrm{~h}$ e $22 \mathrm{~h}$ superou os limites estabelecidos na pesquisa, observou-se a presença de uma ilha de calor na extensão do centro da cidade, avançando sobre o contorno Sul metropolitano de Maringá. 
Em todos os episódios dos transectos, as temperaturas no início foram menores e a umidade relativa do ar maiores, sobressaindo deste ponto sua localização mais afastada, a maior presença de vegetação e o uso agrícola da terra. O ponto final do transecto também registrou temperaturas menores e umidade relativa do ar em ascensão, mas possui características distintas do seu ponto oposto, como a presença de pavimentação. Trata-se da extensão da Avenida Carmem Miranda em direção às Chácaras Aeroporto, com mais aspectos de transição entre a paisagem urbana e rural, do que homogeneidade espacial. Em todos os episódios, as maiores temperaturas e menores umidades relativas do ar verificaram-se nas passagens pela Avenida Herval e Cerro Azul, ambas de intenso fluxo de veículos e de pessoas, com uso misto predominante, destacando-se o comércio e a prestação de serviços.

Verificou-se com frequência, a redução das temperaturas e aumento da umidade relativa do ar na Avenida Arquiteto Nildo Ribeiro da Rocha, na proximidade com o Hospital Municipal de Maringá, zona 28, com a diminuição tênue da altitude, que em média foi de $532 \mathrm{~m}$, ficando entre $473 \mathrm{~m}$ a $488 \mathrm{~m}$ nesta localização. Em todos os episódios de julho e agosto verificou-se mais intensamente esta dinâmica, porém, na atuação da Massa Polar Atlântica, a diferença entre a menor temperatura registrada na área e a temperatura que a antecedeu ou procedeu no transecto, foi de $2,7^{\circ} \mathrm{C}, 4,1^{\circ} \mathrm{C}$ e $2,9^{\circ} \mathrm{C}$ nos dias 20/07/2016, 27/07/2016 e 22/08/2016, respectivamente. Quanto à umidade, a diferença foi superior a $10 \%$ em todos os dias. No episódio do dia 28/08/2016, sob condições de uma frente estacionária, a diferença foi de $2,8^{\circ} \mathrm{C}$ e $13 \%$. Logo, na ocorrência de sistemas polares, a magnitude desta diferença foi mais significativa.

Dessa forma, é preciso reconhecer que os sete episódios destacados em julho e agosto, tiveram uma acentuada diferença térmica e higrométrica, como se constata na Tabela I, mas somente para os dias 22/08/2016 e 28/08/2016 não é possível dizer que houve uma ilha de calor de magnitude máxima de $5,0^{\circ} \mathrm{C}$ e $6,4^{\circ} \mathrm{C}$, respectivamente, porque a menor temperatura ocorreu na área próxima à zona 28 . Nos demais dias, as menores temperaturas ocorreram no início do transecto, local em que as condições altimétricas são homogêneas em comparação ao perfil do transecto. Houve a formação de uma célula $6,4^{\circ} \mathrm{C}$ mais aquecida na área central em direção à parte sul da cidade no dia 27/07/2016.

Quanto à formação da ilha de frescor na área representada como da zona 28, próxima ao Hospital Municipal, convém ressaltar a existência do córrego Moscados como fator fundamental à justificativa das condições de umidade mais favorecidas no local.

Aikawa e Hiroki (2008) chamam atenção para o fato de que a verificação da menor e da maior temperatura em uma área não pode, a princípio, comprovar a existência de uma ilha de calor, pois isso seria uma generalização. Para evitar esta situação, o mais correto é que a pesquisa busque a evolução metodológica, que se baseia no acompanhamento dessas temperaturas extremas. Há necessidade de 
que os registros se prolonguem em Maringá, para que se observe a dinâmica dos elementos analisados em outras estações, e sob atuação de sistemas, que não os extratropicais.

Por fim, o município cujo traçado inicial foi projetado como cidade-jardim pelo engenheiro Jorge Macedo Vieira, segundo o conceito de Ebener Howard, com o tempo e a necessidade de expandir sua malha urbana, descaracterizou-se dos princípios deste planejamento, reduzindo suas áreas verdes e espaços livres de edificação, cuja "[...] organicidade e funcionalidade se perderam, comprometendo os cursos d'água, a manutenção da cobertura vegetal original, a manutenção de um adequado padrão de qualidade ambiental" (BOVO; AMORIM, 2012, p. 108).

Não é difícil apreender que da experiência do planejamento articulado e focado em qualidade dos espaços ocupados, a gestão urbana local valida atualmente, sobretudo a propaganda dos benefícios ecológicos vivenciados há algum tempo, que não mais se compactuam com o desenvolvimento econômico impulsionado no município.

\section{Considerações finais}

Observou-se a existência da ilha de calor em Maringá, em um percurso selecionado, com a ressalva de que a variação de altitude de uma das áreas onde o transecto foi demarcado, resultou em diferenças térmicas e higrométricas significativas, que devem ser analisadas antes de serem tratadas como resultados. A presença do curso d'água na mesma área, isoladamente não seria fator para se ponderar sob o mesmo ponto de vista da altitude. No entanto, diante da dificuldade em quantificar a influência da altitude e do curso d'água, ambos foram incorporados na decisão de se reavaliar alguns dos valores extremos obtidos nos transectos.

Maringá é denominada "Cidade Verde" desde a década de 1980, sobretudo, pela gestão municipal, que buscou reforçar esta qualidade perante a população, mantendo uma propaganda ecológica reforçada sobre suas áreas verdes e a arborização urbana. A presente pesquisa baseada, sobretudo, em dois elementos climáticos, a temperatura e a umidade relativa do ar, comprovou que o campo térmico e higrométrico do município não é homogêneo em sua extensão delimitada pelo percurso.

Atualmente, obras realizadas nas avenidas Kakogawa e Morangueira, pelas quais os transectos ocorreram, ampliam os possíveis efeitos prejudiciais que a retirada da arborização urbana de grande porte, responsável pelo sombreamento, pela amenização da temperatura e maior evapotranspiração poderá trazer à população em curto prazo, justificada pela busca de maior mobilidade urbana.

\section{Bibliografia}


AIKAWA, Masahide; TAKATOSHI HIRAKI, Jiro Eiho. Evaluation methodology of monthly highest and lowest air temperatures in heat island phenomenon survey. Atmospheric Science Letters, v. 9, n. 4, p. 222-225, out-dez. 2008. Disponível em: <http://onlinelibrary.wiley.com/doi/10.1002/asl.192/abstr act>. Acesso em: 21 jun. 2013.

ALCOFORADO, Maria João; ANDRADE, Henrique. Nocturnal urban heat island in Lisbon (Portugal): main features and modelling attempts. Theoretical and applied climatology, n. 84, p. 151-160, 2006.

AMORIM, Margarete Cristiane de Costa Trindade; SANT'ANNA NETO, João Lima; DUBREUIL, Vincent. Estrutura térmica identificada por transectos móveis e canal termal do Landsat 7 em cidade tropical. Revista de Geografia Norte Grande, Santiago: Pontificia Universidad Católica del Chile, n. 43, p. 65-80, set. 2009. Disponível em: <http://www.scielo.cl>. Acesso em: 5 nov. 2009.

BHERING, Silvio Barge; SANTOS, Humberto Gonçalves dos (Ed.). Mapa de solos do Estado do Paraná: legenda atualizada. Rio de Janeiro: Embrapa Florestas: Embrapa solos: Instituto Agronômico do Paraná, 2008. 74 p.

BOVO, Marcos Clair; AMORIM, Margarete Cristiane de Costa Trindade. A cidade verde, imagens e discursos: o caso de Maringá (PR), Brasil. Ra'e Ga, Curitiba, v. 26, p. 100-127, 2012. Disponível em: <http://revistas.ufpr.br/raega/article/view/30152/19461>. Acesso em: 15 jan. 2017.

BRANDÃO, Ana Maria de Paiva Macedo. O clima urbano na cidade do Rio de Janeiro. 1996. 362 f. Tese (Doutorado em Geografia Física) - Faculdade de Filosofia, Letras e Ciências Humanas, Universidade de São Paulo, São Paulo.

CARRERAS, Carles; MARÍN, Mercedes; MARTÍN-VIDE, Javier; MORENO, Maria del Carmen; SABÍ, Joan. Modificaciones térmicas en las ciudades. Avance sobre la isla de calor en Barcelona. Document's D'análisi Geográfica, n. 17, p. 51-77, 1990. Disponível em: < http://www.raco.cat/index.php/DocumentsAnalisi/article/viewFile/41509/52336>. Acesso em 14 fev. 2017.

CENTRO de Previsão do Tempo e Estudos Climáticos (CPTEC)/ Instituto Nacional de Pesquisas Espaciais (INPE). Análise sinótica. Disponível em: <http://www.cptec.inpe.br/noticias/noticia/129058>. Acesso em: 7 dez. 2016.

Banco de dados de imagens da Divisão de Satélites e Sistemas Ambientais (DSA). Disponível em: <http://satelite.cptec.inpe.br/acervo/goes.formulario.logic>. Acesso em: 7 dez. 2016.

FIALHO, Edson Soares. Ilha de calor em cidade de pequeno porte: caso de Viçosa, na zona da mata mineira. 2009. 259 f. Tese (Doutorado em Geografia) - Departamento de Geografia da Faculdade de Filosofia, Letras e Ciências Humanas, Universidade de São Paulo, São Paulo, jul. 2009. Disponível em: 〈http://www.teses.usp.br/teses/disponiveis/8/8135/tde-22022010-154045/pt-br.php>. Acesso em: 23 jun. 2015.

FRASCA TEIXEIRA, Danielle Cardozo; AMORIM, Margarete Cristiane de Costa Trindade. Perfil térmico noturno de cidade pequena no ambiente tropical em episódios de inverno. Ra'e Ga, Curitiba, v. 36, p. 208-228, abr. 2016. Disponível em: < http://revistas.ufpr.br/raega/article/view/42290/28001>. Acesso em: 2 fev. 2017.

GARTLAND, Lisa. Ilhas de calor: como mitigar zonas de calor em áreas urbanas. Tradução: Silvia Helena Gonçalves. São Paulo: Oficina de Textos, 2010. 248 p.

INSTITUTO Brasileiro de Geografia e Estatística (IBGE). Censos demográficos. Disponível em: < http://www.ibge.gov.br/home/mapa_site/mapa_site.php\#canais>. Acesso em: 7 dez. 2016.

MENDONÇA, Francisco de Assis. O clima e o planejamento urbano de cidade de porte médio e pequeno: proposição metodológica para estudo e aplicação à cidade de Londrina, PR. 1994. 332 f. 
Tese (Doutorado em Geografia Física) - Faculdade de Filosofia, Letras e Ciências Humanas, Universidade de São Paulo, São Paulo.

MINAKI, Cíntia; AMORIM, Margarete Cristiane de Costa Trindade. Clima urbano em Guararapes/SP: episódios de verão e de inverno. Geografia, Rio Claro-SP, v. 32, p. 295-318, 2008.

MONTEIRO, Carlos Augusto de Figueiredo. Teoria e Clima Urbano. São Paulo: IGEOG/USP, 1976. 181 p. (Séries Teses e Monografias, 25).

OKE, Timothy R. City size and urban heat island. Atmospheric environment, New York, v. 7, n. 8, p. 769-779, 1973.

PITTON, Sandra Elisa Contri. As cidades como indicadores de alterações térmicas. 1997. 272 f. Tese (Doutorado em Geografia Física) - Faculdade de Filosofia, Letras e Ciências Humanas, Universidade de São Paulo, São Paulo.

PRATS, José Maria Cuadrat; VICENTE-SERRANO, Sérgio M.; SÁNCHEZ, Miguel Anjel Saz. Los efectos de la urbanización en el clima de Zaragoza (España): la islã de calor y sus factores condicionantes. Boletín de la A.G.E., n. 40, p. 311-327, 2005.

SANTOS, Jeater Waldemar Maciel Correa. O clima urbano de Maringá: ensaio metodológico para cidades de porte médio e pequeno. 1996. 172 f. Dissertação (Mestrado em Geografia Física) Faculdade de Filosofia, Letras e Ciências Humanas, Universidade de São Paulo, São Paulo.

SEZERINO, Maria Lurdes; MONTEIRO, Carlos Augusto de Figueiredo. O campo térmico na cidade de Florianópolis: primeiros experimentos. Geosul, ano V, n. 9, p. 20-60, 1 semestre 1990.

SILVEIRA, Leonor Marcon da. Análise rítmica dos tipos de tempo no Norte do Paraná, aplicada ao clima local de Maringá-PR. 2003. 505 f. Tese (Doutorado em Geografia Física) - Faculdade de Filosofia, Letras e Ciências Humanas, Universidade de São Paulo, 2003.

SOUSA, Ana Maria Rodrigues Monteiro de. O clima urbano do Porto: Contribuição para a definição das estratégias de planeamento e ordenamento do território. 1993. 436 f. Tese (Doutorado em Geografia Física) - Universidade do Porto, FLUP, Porto.

TAVARES, Renato. O clima local de Sorocaba (SP): tendências e análise comparativa cidadecampo. 1997, 205 f. Dissertação (Mestrado em Geografia Física) - Faculdade de Filosofia, Letras e Ciências Humanas, Universidade de São Paulo, São Paulo.

ZAMPARONI, Cleusa Aparecida Gonçalves Pereira. Ilha de calor em Barra de Bugres e Tangará da Serra-MT: uma contribuição ao estudo do clima urbano em cidades de pequeno porte em área tropical. 1995. 99 f. Dissertação (Mestrado em Geografia) - Faculdade de Filosofia, Letras e Ciências Humanas, Universidade de São Paulo, São Paulo. 